\title{
HOT DOMESTIC WATER CONSUMPTION PROFILE OF MULTIAPARTMENT BUILDING AND ITS DEPENDENCY ON EXTERNAL CONDITIONS
}

\author{
Raimunds Selegovskis, Janis Berzins, Edmunds Visockis \\ Latvia University of Life Sciences and Technologies, Latvia \\ raimunds.selegovskis@1lu.lv, janis.berzins@1lu.lv, ems@inbox.lv
}

\begin{abstract}
In order to precisely model the heat consumption of a multiapartment building, not only parameters like area of a building and its thermal properties, location, occupation and etc. are important, but also what kind of Hot Domestic Water (HDW) preparation and circulation system is installed and its condition. This can be critical to accurately determine building heat consumption, because energy needed for space heating has a seasonal trend depending on environmental conditions, but the energy needed for HDW preparation and circulation depends on other circumstances. In modeling multiapartment building heat consumption, energy needed for the HDW system is usually set constant or recalculated by hourly water consumption at best. This can give false data that may result in poorly chosen elements of the system and excess heat consumption. To get more precise data not only time of day, but also seasonal parameters need to be taken into consideration, since heat loses in the HDW circulation system emit energy that is transferred to space heating, but this is dependent on the outside temperature. Also, the inlet cold water temperature changes due to the outside temperature and energy to rise its temperature to needed setpoint of HDW is higher. This paper analyzes the heat consumption of numerous multiple apartment buildings, determines the consumption profile and its relationship with outside temperature. Determined profiles can be used to calculate and model building heat consumption and performance.
\end{abstract}

Keywords: heating, energy, domestic, water, profile.

\section{Introduction}

Modeling a central heating system and its performance in different situations is not only important for new systems, where all possible regimes and situations must be considered, but also in existing systems, where customers' heat consumption patterns change very quickly and effect on the system performance must be understood. Although the amount of energy needed for preparation and circulation of hot domestic water (HDW) in multiapartment buildings internal system is significantly less than one needed for space heating, it is consumed throughout year and can be described as base heat load of a customer. The regulation Nr, 906 "The Regulations Regarding the Sanitary Maintenance of a Residential House" issued by the Cabinet of Ministers states that the temperature of HDW after the heat exchanger must be maintained $+55^{\circ} \mathrm{C}$ [1] at all times, so it may seem that heat load could be easily calculated, but more detailed analysis of HDW consumption data suggests otherwise.

The amount of consumed HDW varies depending on customer habits, day of the week, time of day and even outdoor temperature, since heat loses in the circulation system correlate with the temperature difference between water and surrounding temperature. Other authors do not consider variable heat load for HDW preparation and circulation, or profile it only accordingly to the time of day at best. R. Yao and K. Steemers calculate heat load for HDW by using data of average consumed volume of hot water [2]. Without profiling, only average heat load can be calculated, which does not describe the situation precisely, because, as E. Fuentes et.al. in "A review of domestic hot water consumption profiles for application in systems and buildings energy performance analysis" suggest that average and maximal/minimal heat load can differ in a great deal [3]. If the system's elements are calculated using data of average load, it may cause problems, like cold HDW in peak hours and incorrect temperature regimes. Also, maintenance of a system with poorly chosen elements causes excess costs and work.

Although Ž. Budjko determines the consumption profile [4], it is based on HDW volume consumption, since the circulation line is present in the system, the heat loses are not considered. Tumanova K. and Borodinecs A. have found that actual consumption per inhabitant is much less than suggested by the standard [5], which again points out that calculated data of a house may differ from actual consumption in a great deal.Similar research is performed by Dz. Grasmanis, D. Sovetnikov, D. Baranova in their "Energy performance of domestic hot water systems", but instead of comparing absolute values, consumption is rated on $\mathrm{m} 2$ of residential area [6]. 
The objective of this paper it to analyze data of HDW consumption and heat energy used to prepare and maintain it in multiapartment buildings and create a more precise HDW consumption profile that can be used in further studies.

\section{Materials and methods}

To measure the HDW volume and heat consumption, analyze data and prepare the profile, consumption in three different multiapartment buildings were analyzed:

- Building $1-5304 \mathrm{~m}^{2}, 5$ floors, 96 apartments, 246 habitants,

- Building 2-2510 $\mathrm{m}^{2}, 5$ floors, 48 apartments, 122 habitants,

- Building 3-4005 $\mathrm{m}^{2}, 5$ floors, 64 apartments, 164 habitants.

To measure the HDW consumption and heat energy used to prepare and maintain desired temperature, water and heat meters were introduced into the system. Hot water was metered before heating it to the desired temperature of $55^{\circ} \mathrm{C}$. Water meters were installed in the inlet cold water pipe before the heat exchanger:

- Zehner, rotary blade, $Q_{\text {nom }} 2.5 \mathrm{~m}^{3} \cdot \mathrm{h}^{-1}$, max error: $\pm 5 \%$, $\max$ temp.: $+30^{\circ} \mathrm{C}$.

Heat meterswere installed in the supply pipeline before the heat exchanger with temperature sensors in supply and return pipes:

- Kamstrup Multical 602, ultrasonic, $Q_{n o m} 2.5 \mathrm{~m}^{3} \cdot \mathrm{h}^{-1}$, $\max$ error: $\pm\left(0,5+\Delta \Theta_{\min } / \Delta \Theta\right) \%$, max temp. $-180^{\circ} \mathrm{C}$

Meters were read and transmitted to the cloud by MetBox units. Period of reading - 20 minutes.

Hourly outdoor temperature data were collected from the meteorological station in Jelgava, supplied by the State Limited Liability Company "Latvian Environment, Geology and Meteorology Centre".

Consumption data of the three buildings were collected during 2019. The monthly consumption data and average outdoor temperature data are shown in Table 1.

HDW (heat and volume) consumption in 2019 and average outdoor temperature

Table 1

\begin{tabular}{|c|c|c|c|c|c|c|c|c|c|c|c|c|c|c|c|}
\hline & \multicolumn{14}{|c|}{ Month } \\
\hline & & 1 & 2 & 3 & 4 & 5 & 6 & 7 & 8 & 9 & 10 & 11 & 12 & Total & $\operatorname{corr}(\mathrm{X}, \mathrm{Y})$ \\
\hline \multicolumn{2}{|c|}{$\begin{array}{c}\text { Outside } \\
\text { temperature, }{ }^{\circ} \mathrm{C}\end{array}$} & -4.3 & 1.1 & 2.8 & 8.3 & 12.2 & 19.1 & 16.6 & 17.2 & 12.6 & 8.9 & 4.5 & 2.6 & & \\
\hline \multirow{2}{*}{ Building 1} & MWh & 23.3 & 20.7 & 22.6 & 20.4 & 22.6 & 19.6 & 20.8 & 20.6 & 21.8 & 21.8 & 22.4 & 23.7 & 260.2 & -0.66 \\
\hline & $\mathrm{m} 3$ & 160.9 & 139.8 & 154.7 & 153.5 & 134.8 & 107.9 & 117.5 & 120.5 & 125.4 & 112.6 & 108.0 & 131.6 & 1567.0 & -0.65 \\
\hline \multirow{2}{*}{ Building 2} & MWh & 8.3 & 7.5 & 8.1 & 7.7 & 7.7 & 6.5 & 6.7 & 6.7 & 6.8 & 7.2 & 7.3 & 7.8 & 88.1 & -0.88 \\
\hline & $\mathrm{m} 3$ & 75.9 & 74.4 & 78.9 & 74.4 & 71.7 & 56.3 & 56.9 & 60.8 & 63.6 & 70.1 & 67.4 & 70.7 & 821.1 & -0.84 \\
\hline \multirow{2}{*}{ Building 3} & MWh & 17.3 & 15.5 & 17.2 & 16.4 & 17.3 & 14.9 & 15.6 & 15.4 & 16.3 & 17.3 & 15.8 & 18.9 & 197.9 & -0.55 \\
\hline & $\mathrm{m} 3$ & 113.3 & 104.7 & 114.4 & 100.2 & 98.9 & 83.7 & 85.0 & 85.7 & 92.6 & 98.6 & 88.4 & 98.3 & 1163.8 & -0.82 \\
\hline \multirow{2}{*}{ Total } & MWh & 48.8 & 43.8 & 47.8 & 44.5 & 47.6 & 40.9 & 43.1 & 42.8 & 44.9 & 46.2 & 45.6 & 50.3 & 546.2 & -0.71 \\
\hline & $\mathrm{m} 3$ & 350.0 & 318.9 & 348.0 & 328.1 & 305.5 & 247.9 & 259.4 & 266.9 & 281.7 & 281.3 & 263.7 & 300.6 & 3551.9 & -0.77 \\
\hline
\end{tabular}
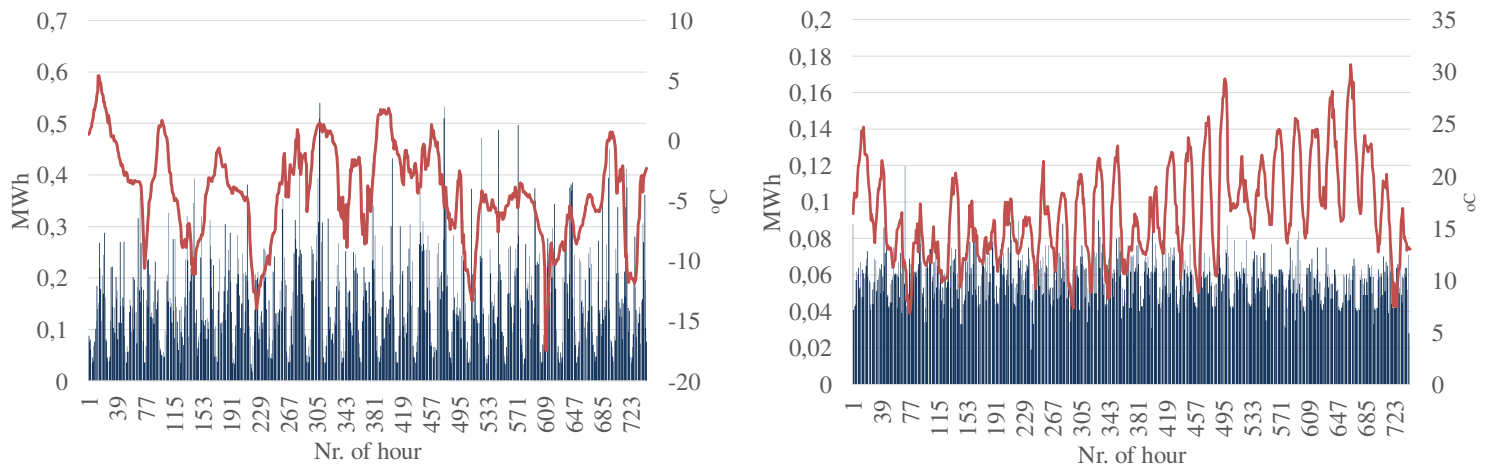

Fig. 1. Combined HDW energy consumption of January and July and outdoor temperature 
The data show that HDW consumption both volume and energy have seasonal character. Correlation between the outside temperature $(X)$ and HDW consumption $(Y)$ shows negative relationship between the data. It is stronger with volume consumption, but is also present with energy consumption.

To perform more detailed analysis on the HDW consumption dependency on the outdoor temperature, data collected in two separate months January and July of both - energy and volume were analyzed. These particular months were chosen because of significant outdoor temperature difference, as well as identical number of days. The consumption data are shown in Fig. 1 and Fig. 2.
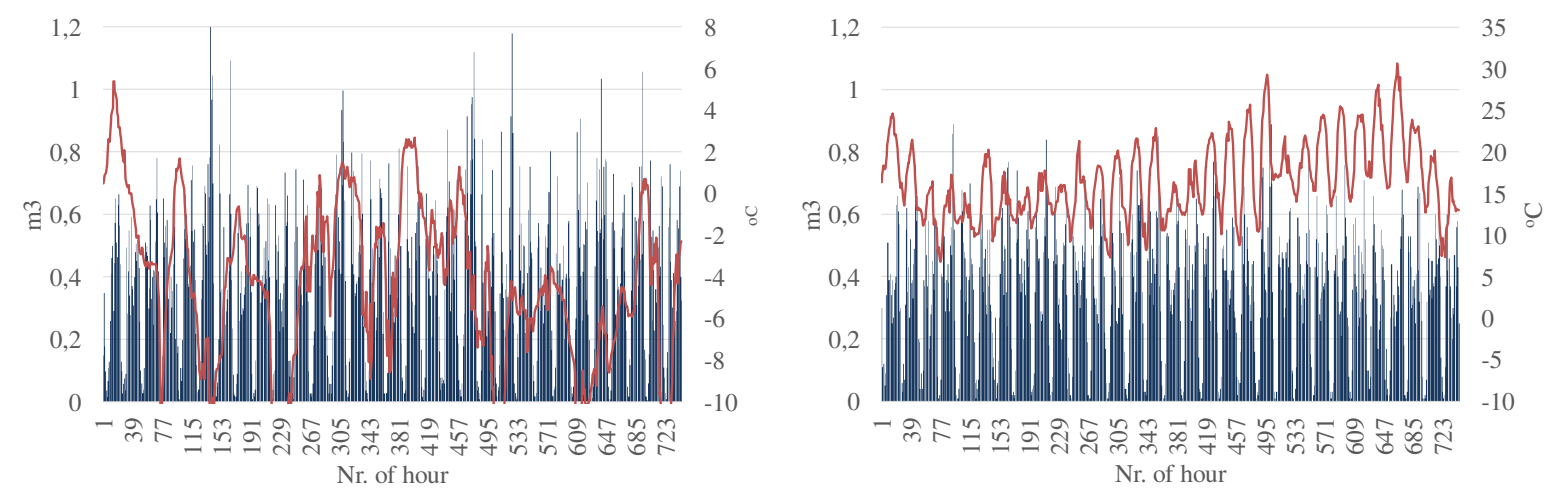

Fig. 2. Combined HDW volume consumption of January and July and outdoor temperature

To understand the relationship between the HDW consumption (both energy and volume) and the outdoor temperature regression, analysis was performed and is shown in Fig. 3.

\section{Results and discussion}

The results show some relationship between the HDW energy consumption and the outdoor temperature data of January and July. Data form two separate clusters since there are no consumption data at missing outside temperatures in between. To analyze the correlation more data needs to be collected.
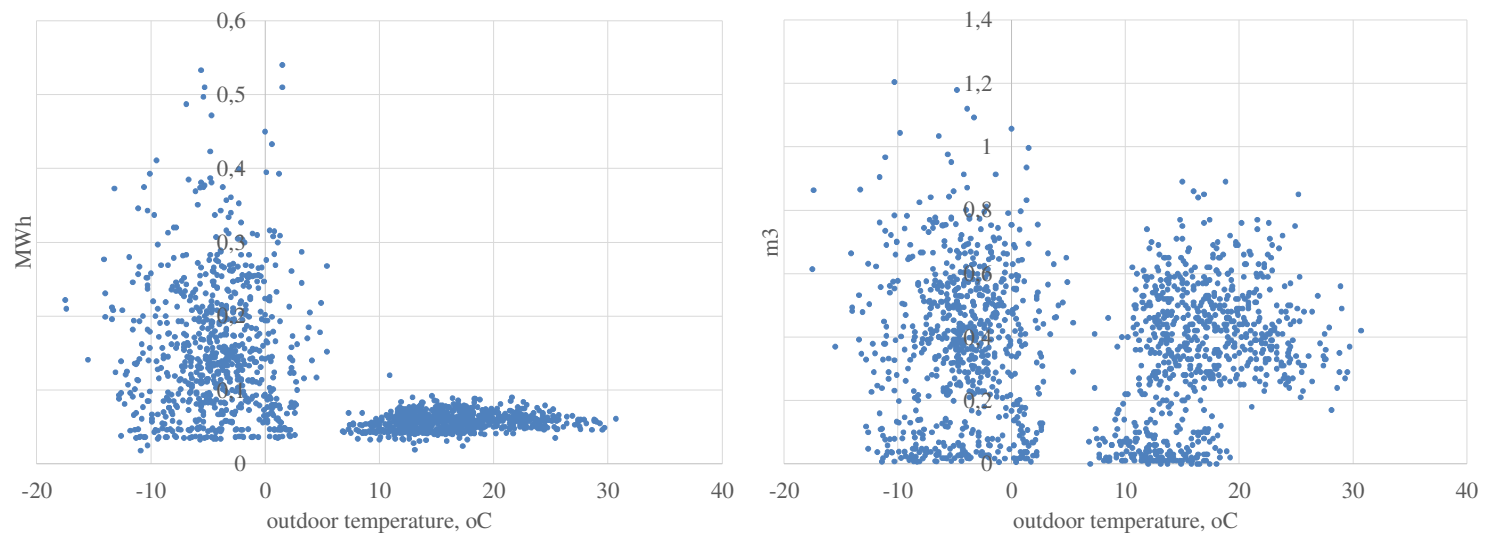

Fig. 3. Regression analysis of HDW energy and volume consumption

Analysis of the HDW volume consumption shows no relationship between the hot water volume and the outdoor temperature. This also could explain the difference with the energy consumption data, higher in the periods with lower outdoor temperature. This could be because of excess heat loses in the HDW circulation line and lower inlet cold water temperature.

In Fig. 1 and Fig 2itcan be seen that HDW consumption has strong relationship with the number of hours, in other words, it correlates with the time of the day.

To understand this, different methods were used. Data were grouped by time and days and also to create more universal profile 1 hour was set as a base unit. To understand if there is a relationship between days, average value was calculated among hourly values and the coefficients of correlation were compared. 
The results in Table 2 show strong correlation between working days, as coefficients vary from corr(time; day $)=0.85-0.98$. The results also show that non workings days do not correlate as strong as working days, since the coefficients as low as corr(time; day) $=0.42$ appear.

Table 2

HDW (heat and volume) consumption average hourly values among days and its correlation

\begin{tabular}{|c|c|c|c|c|c|c|c|}
\hline \multicolumn{7}{|c|}{ MWh } \\
\hline time & Mon & Tue & Wed & Thur & Fri & Sat & Sun \\
\hline $00: 00$ & 0.053 & 0.057 & 0.054 & 0.069 & 0.071 & 0.080 & 0.061 \\
\hline $01: 00$ & 0.052 & 0.054 & 0.045 & 0.043 & 0.074 & 0.050 & 0.069 \\
\hline $02: 00$ & 0.050 & 0.046 & 0.043 & 0.042 & 0.043 & 0.045 & 0.043 \\
\hline $03: 00$ & 0.046 & 0.045 & 0.043 & 0.046 & 0.044 & 0.045 & 0.051 \\
\hline $04: 00$ & 0.062 & 0.058 & 0.065 & 0.058 & 0.044 & 0.050 & 0.062 \\
\hline $05: 00$ & 0.086 & 0.068 & 0.091 & 0.068 & 0.072 & 0.064 & 0.052 \\
\hline $06: 00$ & 0.162 & 0.144 & 0.148 & 0.120 & 0.144 & 0.078 & 0.053 \\
\hline $07: 00$ & 0.129 & 0.116 & 0.140 & 0.158 & 0.143 & 0.080 & 0.068 \\
\hline $08: 00$ & 0.100 & 0.092 & 0.135 & 0.124 & 0.108 & 0.128 & 0.142 \\
\hline $09: 00$ & 0.093 & 0.093 & 0.112 & 0.118 & 0.124 & 0.164 & 0.140 \\
\hline $10: 00$ & 0.090 & 0.090 & 0.100 & 0.087 & 0.111 & 0.145 & 0.142 \\
\hline $11: 00$ & 0.083 & 0.107 & 0.096 & 0.104 & 0.101 & 0.181 & 0.164 \\
\hline $12: 00$ & 0.081 & 0.130 & 0.113 & 0.087 & 0.091 & 0.145 & 0.137 \\
\hline $13: 00$ & 0.086 & 0.100 & 0.109 & 0.106 & 0.086 & 0.151 & 0.109 \\
\hline $14: 00$ & 0.080 & 0.120 & 0.112 & 0.102 & 0.108 & 0.134 & 0.125 \\
\hline $15: 00$ & 0.079 & 0.092 & 0.077 & 0.097 & 0.093 & 0.126 & 0.127 \\
\hline $16: 00$ & 0.085 & 0.100 & 0.092 & 0.100 & 0.103 & 0.142 & 0.144 \\
\hline $17: 00$ & 0.124 & 0.127 & 0.149 & 0.138 & 0.131 & 0.140 & 0.221 \\
\hline $18: 00$ & 0.146 & 0.146 & 0.167 & 0.172 & 0.169 & 0.140 & 0.215 \\
\hline $19: 00$ & 0.139 & 0.164 & 0.172 & 0.163 & 0.157 & 0.153 & 0.237 \\
\hline $20: 00$ & 0.141 & 0.172 & 0.150 & 0.245 & 0.150 & 0.153 & 0.221 \\
\hline $21: 00$ & 0.110 & 0.156 & 0.151 & 0.139 & 0.127 & 0.133 & 0.151 \\
\hline $22: 00$ & 0.116 & 0.110 & 0.094 & 0.114 & 0.098 & 0.101 & 0.126 \\
\hline $23: 00$ & 0.072 & 0.074 & 0.090 & 0.087 & 0.114 & 0.085 & 0.128 \\
\hline & & & & & & & \\
\hline
\end{tabular}

\begin{tabular}{|c|c|c|c|c|c|c|c|}
\hline \multicolumn{7}{|c|}{$\mathbf{m 3}$} \\
\hline time & Mon & Tue & Wed & Thur & Fri & Sat & Sun \\
\hline $00: 00$ & 0.152 & 0.124 & 0.139 & 0.101 & 0.165 & 0.172 & 0.148 \\
\hline $01: 00$ & 0.044 & 0.069 & 0.042 & 0.050 & 0.039 & 0.050 & 0.070 \\
\hline $02: 00$ & 0.035 & 0.042 & 0.019 & 0.024 & 0.020 & 0.042 & 0.058 \\
\hline $03: 00$ & 0.018 & 0.035 & 0.032 & 0.023 & 0.026 & 0.045 & 0.030 \\
\hline $04: 00$ & 0.069 & 0.060 & 0.066 & 0.048 & 0.049 & 0.052 & 0.031 \\
\hline $05: 00$ & 0.216 & 0.161 & 0.201 & 0.195 & 0.195 & 0.099 & 0.059 \\
\hline $06: 00$ & 0.557 & 0.387 & 0.503 & 0.497 & 0.489 & 0.217 & 0.144 \\
\hline $07: 00$ & 0.572 & 0.551 & 0.582 & 0.533 & 0.601 & 0.350 & 0.250 \\
\hline $08: 00$ & 0.505 & 0.492 & 0.512 & 0.499 & 0.520 & 0.514 & 0.428 \\
\hline $09: 00$ & 0.442 & 0.410 & 0.488 & 0.454 & 0.455 & 0.612 & 0.512 \\
\hline $10: 00$ & 0.384 & 0.396 & 0.410 & 0.391 & 0.434 & 0.600 & 0.611 \\
\hline $11: 00$ & 0.394 & 0.381 & 0.342 & 0.371 & 0.401 & 0.549 & 0.637 \\
\hline $12: 00$ & 0.402 & 0.336 & 0.409 & 0.427 & 0.374 & 0.482 & 0.515 \\
\hline $13: 00$ & 0.331 & 0.370 & 0.314 & 0.368 & 0.341 & 0.515 & 0.487 \\
\hline $14: 00$ & 0.332 & 0.337 & 0.294 & 0.324 & 0.329 & 0.362 & 0.476 \\
\hline $15: 00$ & 0.344 & 0.375 & 0.333 & 0.276 & 0.346 & 0.348 & 0.468 \\
\hline $16: 00$ & 0.384 & 0.451 & 0.358 & 0.363 & 0.356 & 0.447 & 0.548 \\
\hline $17: 00$ & 0.493 & 0.500 & 0.439 & 0.487 & 0.466 & 0.451 & 0.580 \\
\hline $18: 00$ & 0.513 & 0.511 & 0.460 & 0.479 & 0.509 & 0.464 & 0.723 \\
\hline $19: 00$ & 0.579 & 0.627 & 0.472 & 0.590 & 0.477 & 0.527 & 0.741 \\
\hline $20: 00$ & 0.634 & 0.620 & 0.579 & 0.663 & 0.503 & 0.427 & 0.770 \\
\hline $21: 00$ & 0.535 & 0.725 & 0.587 & 0.659 & 0.495 & 0.457 & 0.730 \\
\hline $22: 00$ & 0.484 & 0.570 & 0.493 & 0.537 & 0.446 & 0.434 & 0.600 \\
\hline $23: 00$ & 0.267 & 0.249 & 0.301 & 0.284 & 0.273 & 0.285 & 0.356 \\
\hline
\end{tabular}

\begin{tabular}{|c|c|c|c|c|c|c|c|}
\hline $\begin{array}{c}\text { Corr } \\
\text { (time;day) }\end{array}$ & 1.000 & 0.861 & 0.912 & 0.845 & 0.891 & 0.421 & 0.556 \\
\hline- & - & 1.000 & 0.910 & 0.870 & 0.861 & 0.654 & 0.731 \\
\hline- & - & - & 1.000 & 0.858 & 0.913 & 0.602 & 0.701 \\
\hline- & - & - & - & 1.000 & 0.867 & 0.595 & 0.736 \\
\hline- & - & - & - & - & 1.000 & 0.597 & 0.713 \\
\hline- & - & - & - & - & - & 1.000 & 0.809 \\
\hline- & - & - & - & - & - & - & 1.000 \\
\hline
\end{tabular}

\begin{tabular}{|c|c|c|c|c|c|c|c|}
\hline $\begin{array}{c}\text { Corr } \\
\text { (time;day) }\end{array}$ & 1.000 & 0.948 & 0.980 & 0.980 & 0.978 & 0.765 & 0.765 \\
\hline- & - & 1.000 & 0.945 & 0.971 & 0.927 & 0.787 & 0.851 \\
\hline- & - & - & 1.000 & 0.979 & 0.980 & 0.779 & 0.746 \\
\hline- & - & - & - & 1.000 & 0.951 & 0.782 & 0.807 \\
\hline- & - & - & - & - & 1.000 & 0.815 & 0.750 \\
\hline- & - & - & - & - & - & 1.000 & 0.885 \\
\hline- & - & - & - & - & - & & 1.000 \\
\hline
\end{tabular}

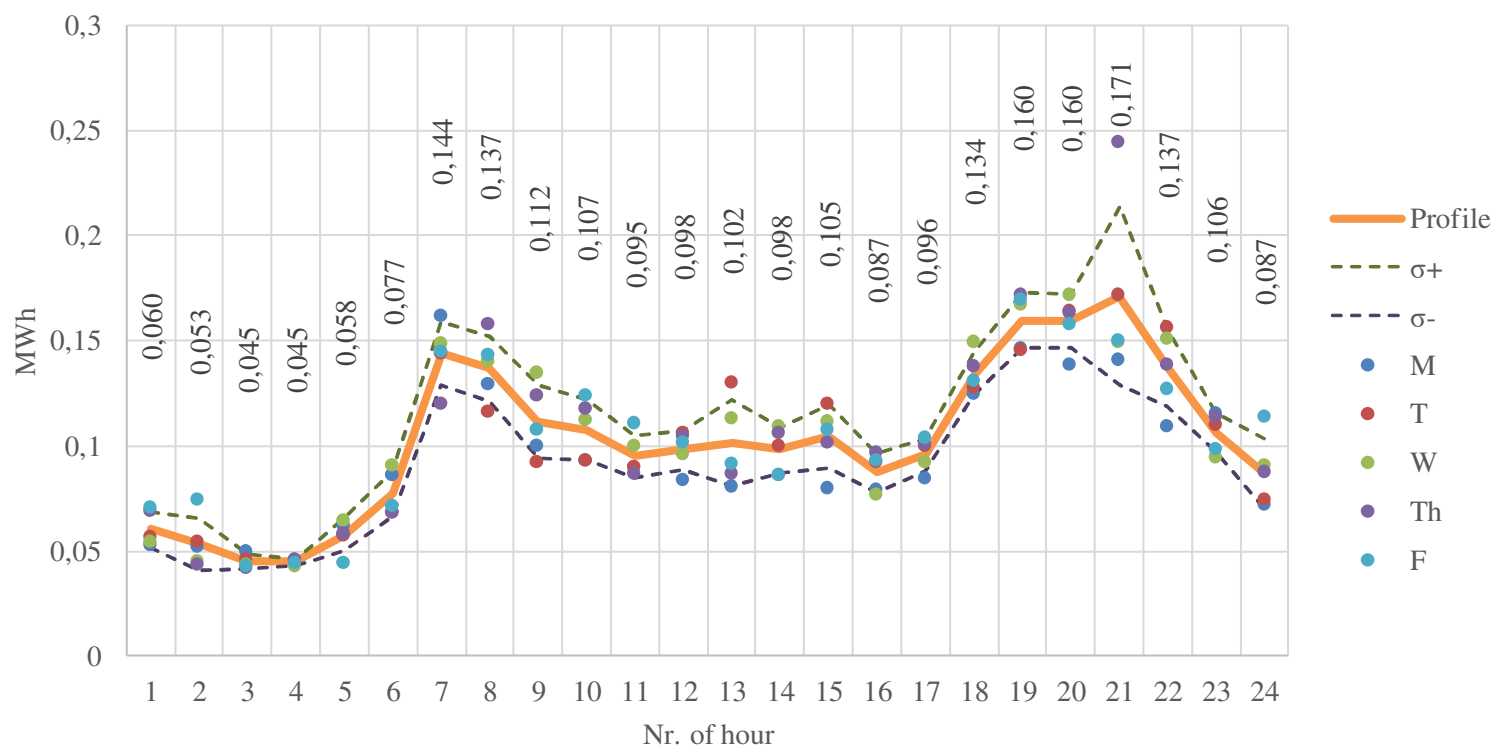

Fig. 4. HDW energy consumption profile for working days 
Regarding this, in further calculations to create a HDW consumption profile two separate cases were considered - working and non-working days. HDW consumption profiles were created using average data collected in Table 2, also standard deviation values were calculated and plotted. Fig. 4 and Fig. 5 show the HDW energy consumption profile for working and non-working days and the calculated values.

Differences in the HDW energy consumption patterns, visible in Fig. 4 and Fig.5, show tendencies in habits and also point to periods of time, when consumption is partly uncertain. The energy consumption profile shows that in working days morning spike starts around 5:00 - 6:00, but on non-working days it starts at 8:00.

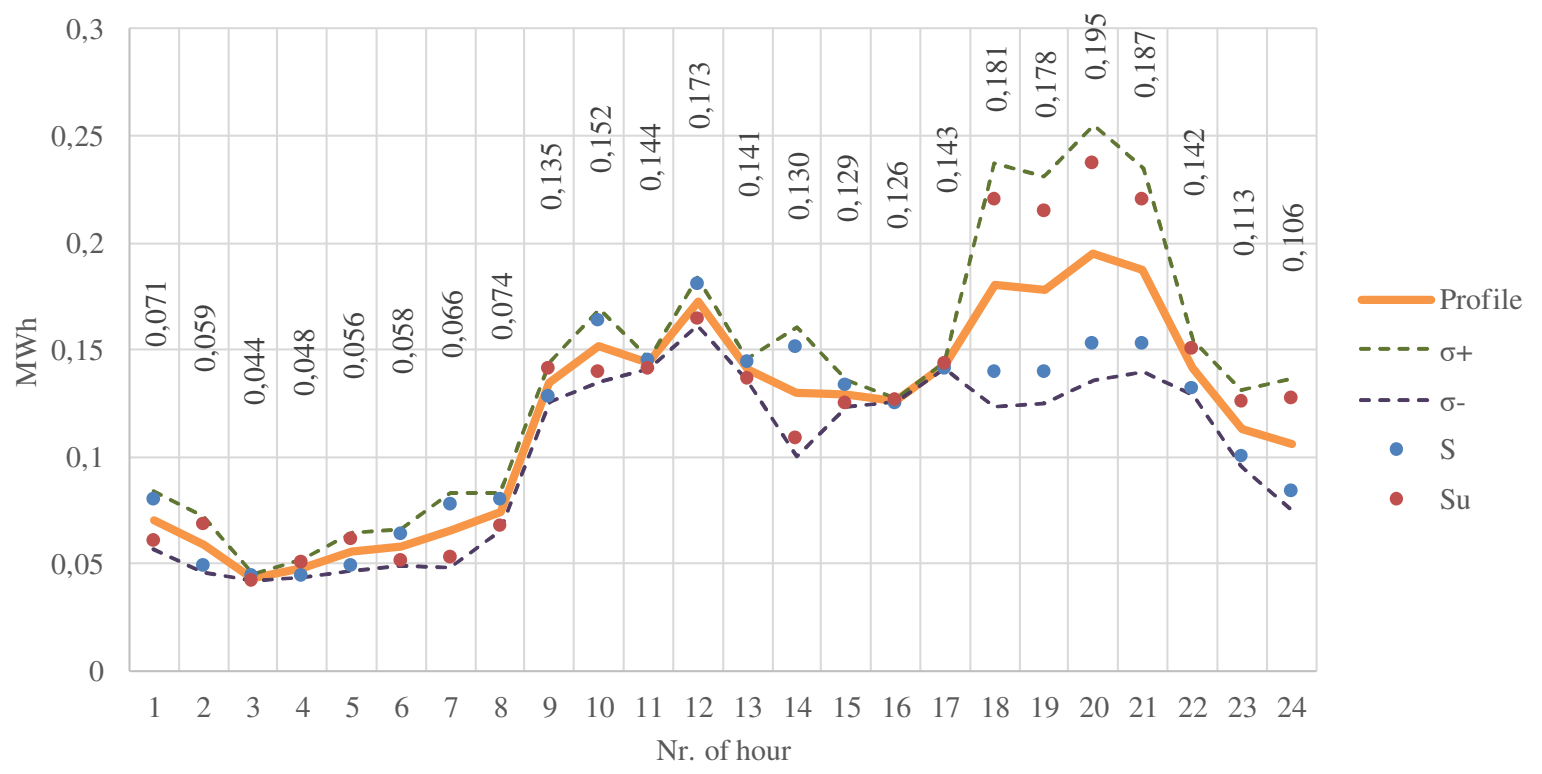

Fig. 5. HDW energy consumption profile for non-working days

The mid-day consumption pattern is lower for both profiles, but duration is much longer on working days from around 11:00 till 17:00 compared to 13:00 till 17:00 on non-working days. Evening spike is similar for both profiles, but uncertainty is much greater in the non-working day profile, since there is significant difference in the Saturday and Sunday consumption pattern from 18:00 till21:00, which could be explained as Saturday evenings are usually less busy, since in Sunday evening preparation for next week starts.

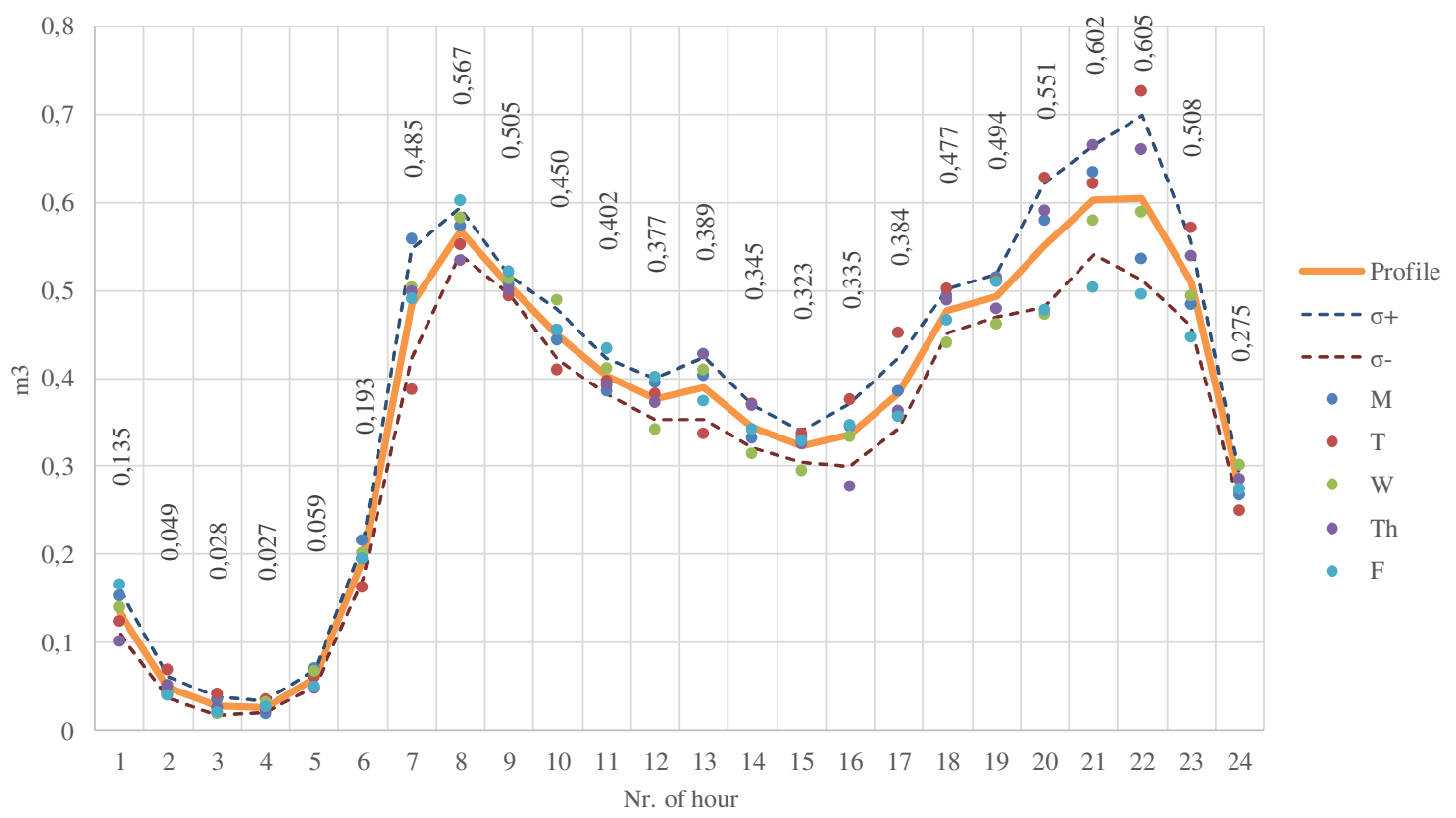

Fig. 6. HDW volume consumption profile for working days 
Similarly, profiles were created for the HWD volume consumption, as seen in Fig. 6 and Fig. 7. Spikes and drops are higher in these profiles, since in night hours consumption is close to $0 \mathrm{~m}^{3}$. Similarly as with energy, also volume spikes during non-working days are longer and continue during day hours compared to working days, when only morning and evening spikes are dramatical.

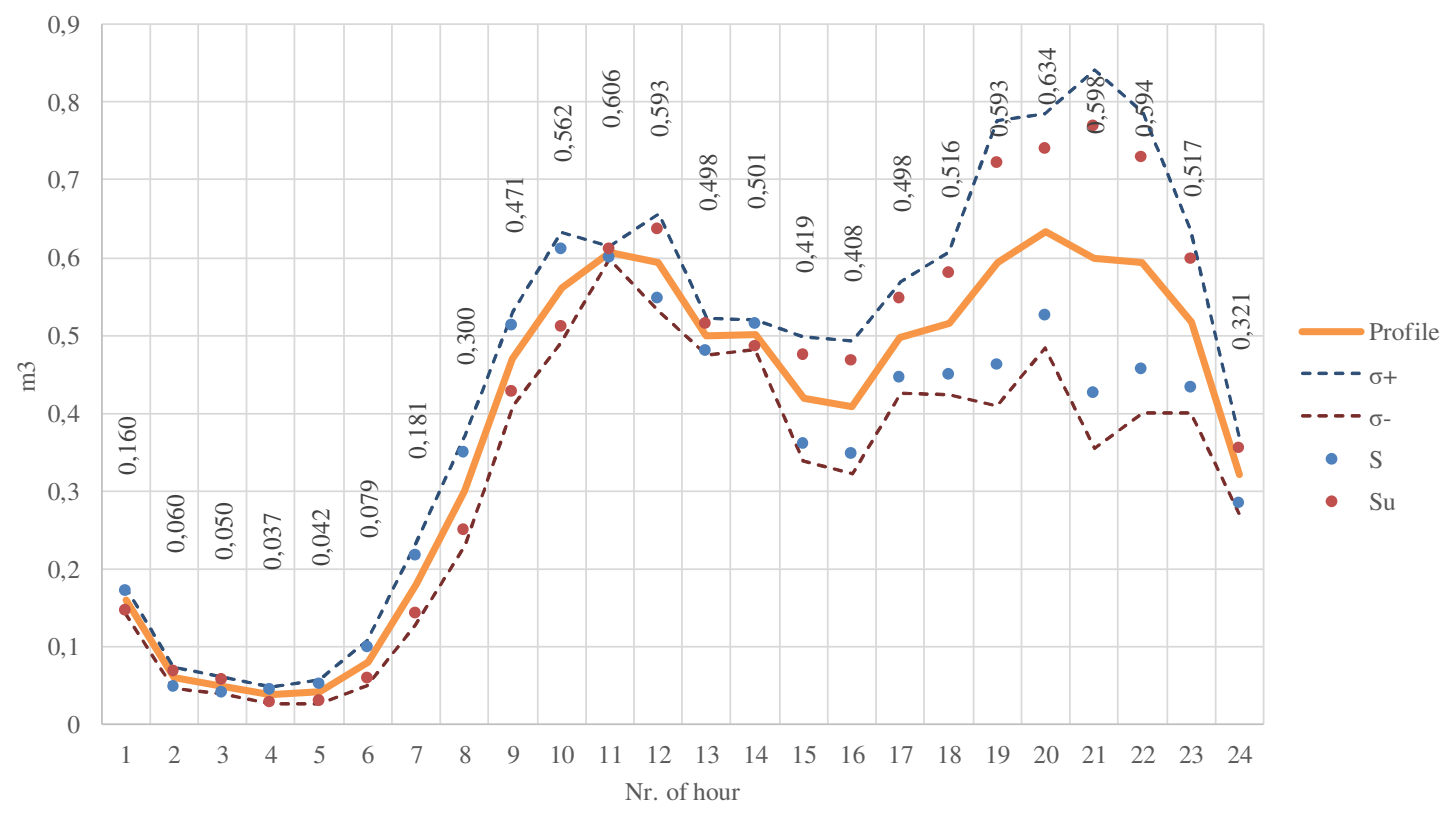

Fig. 7. HDW volume consumption profile for non-working days

\section{Conclusions}

1. Data analysis of monthly HDW energy and volume consumption shows negative relationship with outdoor temperature, since the correlation coefficients vary from -0.55 to -0.88 , sum of consumption shows correlation of -0.71 for energy and -0.77 for volume.

2. Different patterns of data in Fig 3, show that heat loses in hot domestic water circulation system are significant because same analysis of volume shows no relationship. Because of this, heat loses in HDW system should be counted in space heating calculation during heating season.

3. Correlation coefficients of analysis of average HWD consumption show differences in patternduring working and non-working days, since corr(time; day) $=0.85-0.98$ for working days, but it drops as low as corr(time; day) $=0.42$ for non-working days.

4. The created HDW consumption profiles for energy and volume during working and non-working days show that more detailed analysis should be carried out, because uncertainty of the profiles during evening spikes is present.

\section{References}

[1] Cabinet of MinistersThe regulation Nr, 906 "The Regulations Regarding the Sanitary Maintenance of a Residential House". Latvijas Vēstnesis, 156, 01.10.2010.

[2] Yao R., Steemers K., A method of formulating energy load profile for domestic buildings in the UK,Energy and Buildings,Volume 37, Issue 6,2005, pp. 663-671

[3] Fuentes E., Arce L., Salom J. A review of domestic hot water consumption profiles for application in systems and buildings energy performance analysis, Renewable and Sustainable Energy Reviews, Volume 81, Part 1, 2018, pp. 1530-1547.

[4] Budjko Ž., Zēbergs, V. Investigation of the domestic hot water consumption in the apartment building. Scientific Journal of Riga Technical University. Construction Science, 2009, pp. 25-32.

[5] Tumanova, K., Borodinecs, A. Analysis of Centralized Hot Tap Water Systems Calculation's Specifics. No: MATEC Web of Conferences, Russia, Saint-Petersburg, 19.-20.11.,2018. DOI: $10.1051 /$ matecconf/201824506011

[6] Grasmanis D., Baranova D., Sovetnikov D. Energy Performance of Domestic Hot Water Systems. Magazine of Civil Engineering, 2017, No.8, pp.140-155. ISSN 2071-4726. e-ISSN 2071-0305. DOI: 10.18720/MCE.76.13 